\title{
Recurring Gastrointestinal Infections Increase the Risk of Dementia
}

\author{
Anne Fink $^{\mathrm{a}}$, Gabriele Doblhammer ${ }^{\mathrm{a}, \mathrm{b}}$ and Gültekin Tamgüney $\mathrm{c}, \mathrm{d}, *$ \\ ${ }^{a}$ German Center for Neurodegenerative Diseases (DZNE), Bonn, Germany \\ ${ }^{\mathrm{b}}$ Institute for Sociology and Demography, University of Rostock, Rostock, Germany \\ ${ }^{\mathrm{c}}$ Institut für Biologische Informationsprozesse, Strukturbiochemie (IBI-7), Forschungszentrum Jülich GmbH, \\ Jülich, Germany \\ ${ }^{\mathrm{d}}$ Institut für Physikalische Biologie, Heinrich-Heine-Universität Düsseldorf, Düsseldorf, Germany
}

Handling Associate Editor: Suzanne Tyas

Accepted 30 August 2021

Pre-press 25 September 2021

\begin{abstract}
.
Background: Gastrointestinal infections cause significant health problems, including those affecting the immune, musculoskeletal, and nervous system, and are one of the leading causes for death worldwide. Recent findings suggest that microbiota of the gastrointestinal tract contribute to dementia.

Objective: In this nested case-control study we investigated the role of common gastrointestinal infections on the subsequent risk of dementia.

Methods: We used a longitudinal sample of 202,806 individuals from health claims data of the largest German health insurer and applied a nested case-control design with 23,354 initial dementia cases between 2006 and 2014 and 23,354 matched controls. We used conditional logistic regression to compute odds ratios (ORs) for dementia and corresponding $95 \%$ confidence intervals (CIs), adjusting for potential confounders.

Results: The risk of dementia was increased in patients with recurring incidences of quarters with diagnosed gastrointestinal infections when compared to the unexposed population (one quarter: $\mathrm{OR}=1.49,95 \% \mathrm{CI}=1.40-1.58$; two quarters: $\mathrm{OR}=1.70$, $95 \% \mathrm{CI}=1.51-1.91$; three or more quarters: $\mathrm{OR}=1.64,95 \% \mathrm{CI}=1.40-1.93$ ), adjusted for potential confounders.

Conclusion: Our findings suggest that recurring gastrointestinal infections are associated with an increased risk of subsequent dementia.
\end{abstract}

Keywords: Alzheimer's disease, dementia, gastrointestinal microbiome, risk

\section{INTRODUCTION}

The microbiome of the human gastrointestinal tract has attracted great attention because recent discoveries have shown that it affects human development and health in multiple and previously unimaginable

\footnotetext{
*Correspondence to: Gültekin Tamgüney, Institut für Biologische Informationsprozesse, Strukturbiochemie (IBI-7), Forschungszentrum Jülich GmbH, Wilhelm-Johnen-Straße, 52425, Jülich, Germany. Tel.: +49 151 61324989; E-mail: erdem@fz-jue lich.de.
}

ways, playing a role, for instance, in obesity, cancer, autoimmune diseases, and autism spectrum disorders [1-4]. The influence of the gut microbiome on the development, aging, and degeneration of the central nervous system (CNS), the microbiota-gut-brain axis, is still only poorly understood and remains to be fully explored [1, 5]. Recently, we showed that dysbiosis of the gastrointestinal tract in form of gastrointestinal infections (GIIs) increases the subsequent risk of Parkinson's disease (PD), the second most common neurodegenerative disorder after Alzheimer's disease 
(AD) [6]. Dementia patients with AD have an altered gut microbiome with a decreased microbial diversity, which is replicated in animal models of AD [7-10]. Moreover, antibiotic treatment-induced changes in microbiota composition as well as microbial deficiency in germ-free mice have been associated with reduced neuropathology in AD $[9,11-13]$. The major pathogens causing GIIs are viruses, bacteria, and protozoa, which often remain unidentified. GIIs can cause gastroenteritis and colitis, also known as infectious diarrhea, which is an acute inflammatory condition of the GI tract with symptoms of diarrhea, vomiting, and abdominal pain [14]. Symptoms typically last less than two weeks and most cases resolve within $24-48 \mathrm{~h}$ after contracting the infectious agent. GIIs cause significant health problems and are one of the leading causes for death worldwide, especially among children of the developing world [15]. Many acute and chronic consequences have been ascribed to GIIs, including those affecting the immune, musculoskeletal, and the nervous system [16, 17]. Intrigued by our earlier findings, we wondered if GIIs could also have an effect on more prevalent neurodegenerative conditions such as dementia. With an extensive impact on individuals, families, and the healthcare system, the etiology of dementia is of increasing concern. According to a recent estimate from the World Alzheimer Report 2019 the global number of people with dementia is over 50 million and is estimated to increase to 152 million by 2050 [18]. Dementia is defined as deterioration in memory, thinking, and behavior affecting a patient's daily functioning and independent living. The most common types of dementia are neurodegenerative and include $\mathrm{AD}$, vascular dementia, frontotemporal dementia, Lewy body dementia, and PD with dementia, which are all collectively irreversible and usually progressive. Among the dementias, AD is the most common and contributes to $60-80 \%$ of all cases [19]. Vascular dementia, the second most common type of dementia causing up to $15 \%$ of all cases, is caused by vascular injury or disease within the brain and may predispose some individuals to acquire $\mathrm{AD}$, or may exacerbate the clinical course of $\mathrm{AD}$, and thus frequently coexists with $\mathrm{AD}[20,21]$. Clinical, epidemiological, genetic, and neuropathological studies show that the causes for dementia are complex. The strongest risk factor for developing dementia is advancing age [22]. For AD, the major genetic risk factor is presence of the $\varepsilon 4$ allele of apolipoprotein $\mathrm{E}(A P O E)$ [23]. Other risk factors contributing to cognitive decline and dementia are family history, depression, physical frailty, low educational attainment, poor social relationships, smoking, cardiovascular disease, hypercholesterolemia, diabetes mellitus, hypertension, cerebrovascular disease, and intracranial injury [20]. To our best knowledge there is no population study which has investigated the impact of GIIs, including gastroenteritis and colitis, on dementia. In the present nested case-control study using population-based data, we investigated the risk of dementia in patients who previously suffered from GIIs compared to unexposed counterparts.

\section{METHODS}

\section{Data source}

We used a random longitudinal sample $(\mathrm{N}=$ 250,000) of insured individuals born before 1955 of Germany's largest public sickness fund, the Allgemeine Ortskrankenkasse (AOK). The sample was drawn in the first quarter of 2004 and followed up until the end of 2015. The data consisted of a demographic part with information on gender, year and month of birth and death if applicable, place of living, and whether the individual lived in an institution or not. The second part contained information on all reimbursed inpatient and outpatient diagnoses coded by the German modification of the 10th revision of the International Statistical Classification of Diseases and Related Health Problems (ICD-10). A third part contained information on all filled prescriptions from the outpatient sector coded by the Anatomical Therapeutic Chemical (ATC) classification system. All information was available on a quarterly basis.

\section{Selection of cases and controls}

We used data of 202,806 individuals aged 50 and older who had no diagnosis of dementia, no diagnosis of PD (ICD-10: G20), and no diagnosis of stroke or complications of stroke (ICD-10: I63-I64, I69.3, I69.4) in their medical history during the years 2004 and 2005. We excluded persons with previous diagnoses of PD or stroke because they are more likely to develop a subsequent dementia due to those pre-existing illnesses, which could bias our analysis. From among the 202,806 individuals in our analysis sample 23,354 were diagnosed with dementia between the beginning of 2006 and the end of 2014 (Fig. 1).

We defined dementia as having at least one of the following ICD-10 codes: dementia in AD (F00); 


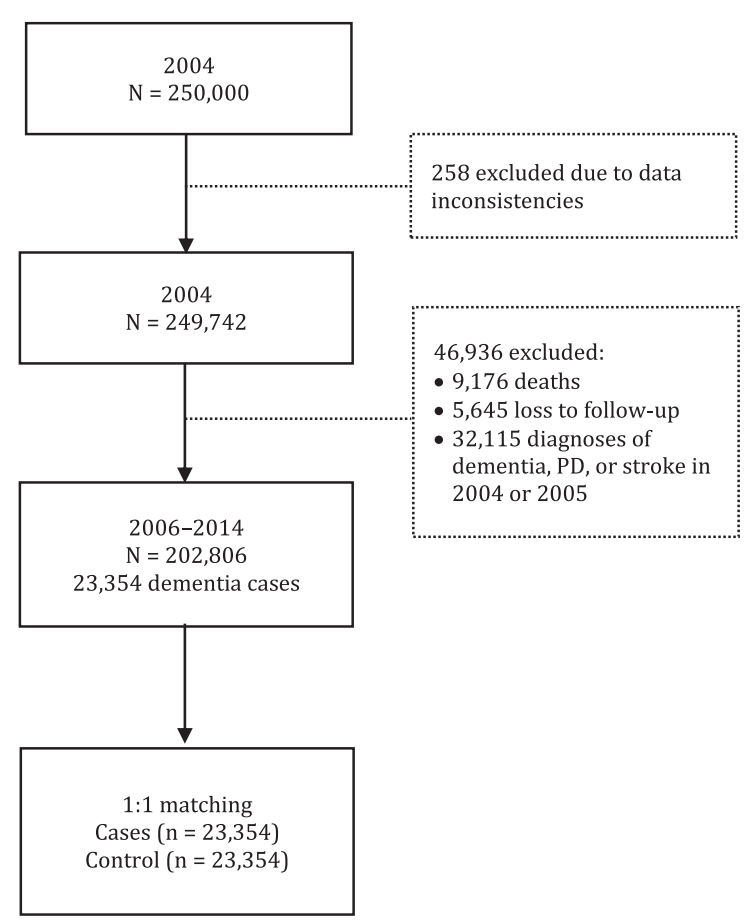

Fig. 1. Inclusion of patients and controls in the analyses.

vascular dementia (F01); dementia in other diseases classified elsewhere (F02); unspecified dementia (F03); delirium superimposed on dementia (F05.1); AD (G30); and circumscribed brain atrophy (G31.0). We applied an established two-stage validation strategy to overcome the problem of false-positive diagnoses $[24,25]$. In the first stage, "verified" outpatient diagnoses as well as inpatient discharge or secondary diagnoses were identified. In the second stage, the diagnoses were confirmed by a simultaneous in- and outpatient diagnosis, by two diagnoses from two different types of physicians within the same quarter, or by co-occurrence over the study period plus the year 2015, which was only used for validation. A diagnosis was also considered valid if an individual died within the same quarter during which dementia was diagnosed for the first time. All persons were censored at the time of death, attrition, or at the end of 2014. The date of the first diagnosis is subsequently referred to as the diagnosis date. Each dementia case was matched to one control by age (in ten-year age groups), gender, and time since observation using incidence density sampling (Stata command sttocc). For the controls, the index date was set to the date of dementia diagnosis of the matched cases.

\section{Exposures}

We defined GIIs as having one of the ICD-10 codes for intestinal infectious diseases (A00-A09). We only considered "verified" outpatient diagnoses and inpatient discharge or secondary diagnoses. Here, we did not follow an internal validation strategy by assuming at least two diagnoses. GIIs are often short-term and very acute diseases that are rarely confirmed by a second physician. We focused on the cumulative number of quarters with a GII diagnosis and distinguished between persons without a GII, and persons with one quarter, two quarters, and three and more quarters with GIIs from the start of observation until the date of diagnosis/index date.

\section{Covariates}

We adjusted our regression models for prescriptions of antibacterials (AB) for systemic use (ATC code: J01). We distinguish between persons who have never had a prescription for $\mathrm{AB}$ and persons that have had at least one prescription for AB. Further, we controlled for important chronic comorbidities including diabetes mellitus (E10-E14), cerebrovascular diseases (I60-I69), hypertension (I10-I15), ischemic heart diseases (I20-I25), hypercholesterolemia (E78.0), intracranial injury (S06), atrial fibrillation (I48), noninfective enteritis and colitis (K50-K52), acute infections of the urinary tract (N30, N33, N37, N39), and pneumonia (J12-J18), and whether the patients were living in a nursing home or not.

\section{Statistical analysis}

To assess the association between GIIs and dementia, we used conditional logistic regression models. Model 1 considers the cumulative number of quarters with a GII diagnosis. Model 2 additionally controls for prescriptions of $\mathrm{AB}$ for systemic use. In model 3, we combined information on the cumulative number of quarters with GIIs and $\mathrm{AB}$ in one categorical variable to distinguish between a) persons without GIIs and without $\mathrm{AB}, \mathrm{b}$ ) persons with one GII quarter and without $A B, c)$ persons with two GII quarters and without $A B, d$ ) persons with three or more GII quarters and without $\mathrm{AB}, \mathrm{e}$ ) persons without GIIs and with $\mathrm{AB}, \mathrm{f})$ persons with one GII quarter and with $\mathrm{AB}, \mathrm{g}$ ) persons with two GII quarters and with $A B$, and $h$ ) persons with three or more GII quarters and with $\mathrm{AB}$. 
Table 1

Characteristics of case patients and matched controls

\begin{tabular}{|c|c|c|c|c|}
\hline \multirow[t]{3}{*}{ Characteristics } & \multicolumn{4}{|c|}{ Study participants } \\
\hline & \multicolumn{2}{|c|}{ Cases } & \multicolumn{2}{|c|}{ Controls } \\
\hline & $n=23,354$ & $\%$ & $n=23,354$ & $\%$ \\
\hline$\overline{\text { Men }}$ & 7,668 & 32.8 & 7,668 & 32.8 \\
\hline Women & 15,686 & 67.2 & 15,686 & 67.2 \\
\hline \multicolumn{5}{|l|}{ Age in years at diagnosis/index date } \\
\hline $50-59$ & 313 & 1.3 & 313 & 1.3 \\
\hline $60-69$ & 1,600 & 6.9 & 1,600 & 6.9 \\
\hline $70-79$ & 7,625 & 32.6 & 7,625 & 32.6 \\
\hline $80-89$ & 10,876 & 46.6 & 10,876 & 46.6 \\
\hline$\geq 90$ & 2,940 & 12.6 & 2,940 & 12.6 \\
\hline \multicolumn{5}{|c|}{ Number of quarters with a GII until diagnosis/index date since 2004} \\
\hline 0 & 18,981 & 81.3 & 20,322 & 87.0 \\
\hline 1 & 3,238 & 13.9 & 2,317 & 9.9 \\
\hline 2 & 753 & 3.2 & 470 & 2.0 \\
\hline$\geq 3$ & 382 & 1.6 & 245 & 1.0 \\
\hline \multicolumn{5}{|c|}{ Prescription of AB until diagnosis/index date since 2004} \\
\hline 0 & 7,093 & 30.4 & 7,715 & 33.0 \\
\hline$\geq 1$ & 16,261 & 69.6 & 15,639 & 67.0 \\
\hline \multicolumn{5}{|c|}{ Chronic comorbidities at diagnosis/index date } \\
\hline Diabetes & 10,636 & 45.5 & 8,497 & 36.4 \\
\hline Cerebrovascular diseases & 9,149 & 39.2 & 5,264 & 22.5 \\
\hline Hypertension & 20,661 & 88.5 & 19,566 & 83.8 \\
\hline Ischemic heart disease & 12,451 & 53.3 & 10,624 & 45.5 \\
\hline Hypercholesterolemia & 7,814 & 33.5 & 7,808 & 33.4 \\
\hline Intracranial injuries & 1,319 & 5.6 & 569 & 2.4 \\
\hline Atrial fibrillation & 6,429 & 27.5 & 4,203 & 18.0 \\
\hline Noninfective enteritis and colitis & 4,656 & 19.9 & 3,555 & 15.2 \\
\hline \multicolumn{5}{|c|}{ Acute comorbidities at diagnosis/index date } \\
\hline Urinary tract diseases & 5,064 & 21.7 & 1,868 & 8.0 \\
\hline Pneumonia & 1,504 & 6.4 & 257 & 1.1 \\
\hline \multicolumn{5}{|c|}{ Institutionalization status at diagnosis/index date } \\
\hline Living at home & 20,190 & 86.5 & 22,757 & 97.4 \\
\hline Living in nursing home & 3,164 & 13.5 & 597 & 2.6 \\
\hline
\end{tabular}

GII, gastrointestinal infection; $\mathrm{AB}$, antibacterials for systemic use

In the fully adjusted model 4 , we controlled for the chronic and acute comorbidities mentioned above as well as for the institutionalization status at the diagnosis/index date. As a sensitivity analysis, we assessed the time since the last GII and distinguished between a) persons that had never had a GII, b) persons with a GII in the quarter of the diagnosis/index date, c) persons with the last GII one to two quarters prior to the diagnosis/index date, and d) persons with the last GII three or more quarters prior to the diagnosis/index date (model 5). All analyses were performed using Stata 16.0 MP (StataCorp LLC).

\section{Data availability}

The data that support the findings of this study are available from the AOK but restrictions apply to the availability of these data, which were used under license for the current study, and so are not publicly available. Data are, however, available from the authors upon reasonable request and with permission of the AOK.

\section{RESULTS}

Inclusion criteria and characteristics of the case patients and matched controls

The base cohort comprised 202,806 individuals aged 50 years and above. During a total of 1,408,787 person-years of follow-up, 23,354 people were diagnosed with dementia. 23,354 case patients and 23,354 matched controls were eligible for inclusion (Fig. 1). Their characteristics are shown in Table 1. During the time until the diagnosis/index date $81.3 \%(18,981)$ of the case patients and $87.0 \%(20,322)$ of the controls 
never had a GII diagnosis. One quarter with a GII was observed among $13.9 \%$ of the case patients and $9.9 \%$ of the controls. Two quarters with a GII were observed among $3.2 \%$ of the case patients and $2.0 \%$ of the controls. Three or more quarters with a GII were observed in $1.6 \%$ of the case patients and $1.0 \%$ of the controls. Prevalence values were higher in case patients than in controls for prescribed $\mathrm{AB}$ and all the comorbidities. At the diagnosis/index date $13.5 \%$ $(3,164)$ of the case patients and $2.6 \%$ (597) of the controls lived in a nursing home.

\section{Multiple preceding quarters with a GII diagnosis increases the risk of dementia}

Model 1 (Table 2) depicts the cumulative effect of multiple preceding quarters with a GII diagnosis on the risk of dementia. Here, exposure of one quarter with a GII diagnosis is associated with a $50 \%$ increased OR for dementia compared to unexposed persons $(p<0.001)$. Two quarters with a GII increased the OR for dementia by a factor of 1.73 $(p<0.001)$, and three or more quarters increased the OR for dementia by a factor of $1.68(p<0.001)$. Adjusted for AB, GIIs did not show a remarkable effect on the OR for dementia, but prescription for $\mathrm{AB}$ was associated with increased ORs for dementia (Table 2, model 2: OR $=1.10, p<0.001$ ). In model 3, we combined the information on quarters with a GII and prescription for $\mathrm{AB}$ and revealed increased ORs for dementia with an increasing number of quarters with a GII among individuals without $\mathrm{AB}$ prescription (Table 2, model 3: 1 GII \& no AB: OR $=1.92$, $p<0.001 ; 2$ GIIs \& no AB: $\mathrm{OR}=2.22, p<0.001 ; \geq 3$ GIIs \& no $\mathrm{AB}$ : $\mathrm{OR}=2.22, p<0.001)$. Among individuals with at least one $A B$ prescription, GIIs also increased the OR for dementia ( 1 GII \& $\geq 1 \mathrm{AB}$ : $\mathrm{OR}=1.59, p<0.001 ; 2$ GIIs $\& \geq 1 \mathrm{AB}: \mathrm{OR}=1.85$, $p<0.001 ; \geq 3$ GIIs $\& \geq 1 \mathrm{AB}: \mathrm{OR}=1.80, p<0.001$ ). Adjusting for all confounding variables revealed that the institutionalization status and all comorbidities, except hypercholesterolemia, were strongly associated with increased ORs for dementia, fully explaining the GII effect among individuals with $\mathrm{AB}$ prescription (Table 2, model 4: 1 GII $\& \geq 1 \mathrm{AB}$ : $\mathrm{OR}=1.02, p=0.632 ; 2$ GIIs $\& \geq 1 \mathrm{AB}: \mathrm{OR}=0.99$, $p=0.926 ; \geq 3$ GIIs $\& \geq 1 \mathrm{AB}: \mathrm{OR}=0.945, p=0.554$ ). However, among persons without an $\mathrm{AB}$ prescription, multiple preceding quarters with a GII diagnosis still increased the risk of dementia ( $1 \mathrm{GII} \&$ no AB: $\mathrm{OR}=1.40, p<0.001 ; 2$ GIIs \& no $\mathrm{AB}: \mathrm{OR}=1.65$, $p=0.017$; $\geq 3$ GIIs \& no $\mathrm{AB}: \mathrm{OR}=1.84, p=0.066$ ).
The risk of dementia remains increased 1-2 quarters after the last documented GII diagnosis

In the sensitivity analysis (Table 3) the risk of dementia of individuals with GIIs remained significantly increased compared to non-exposed individuals after implementing information on times since the last GII diagnosis. Having adjusted the ORs for the risk of dementia for all covariates, we observed increased ORs for dementia when the last GII diagnosis was made in the quarter of the dementia diagnosis/index date $(\mathrm{OR}=2.36, p<0.001)$ compared to non-exposure. A GII diagnosis one to two quarters prior to the diagnosis/index date was associated with an increased OR of $1.23(p=0.013)$. GIIs three or more quarters before the diagnosis/index date did not increase the $\mathrm{OR}$ for dementia $(\mathrm{OR}=1.01, p=0.824)$.

\section{DISCUSSION}

Our findings reveal increased ORs for dementia among individuals with GIIs. The risk of dementia was still significantly increased when adjusted for antibiotics, comorbidities, and institutionalization status. The results of a sensitivity analysis suggest that the risk of dementia after the last documented GII diagnosis remains increased up to two quarters prior to the diagnosis/index date. Our data argue that GIIs increase the subsequent risk of dementia and suggest that gut microbiota can have a strong influence on higher cognitive functions.

How exactly dysbiosis of the gut microbiome results in dementia remains to be clarified. Acute as well chronic GIIs can alter the composition of gut microbiota either directly or through the use of medications such as antibiotics [26]. Sequence analyses comparing the gut microbiome of cognitively impaired elderly and controls have identified significant differences between the two groups that associate brain amyloidosis causing dementia with proinflammatory gut bacterial taxa and peripheral inflammation markers $[8,27]$. Remarkably, gut microbiota directly control the maturation and inflammatory capabilities of microglia in the CNS through the production of small chain fatty acids in the gastrointestinal tract, and the lack of a complex gut microbiota can affect microglia innate immune function [28]. Bacterial and viral neuroinvasion of the CNS could be initiated and further exacerbated by inflammation of the gastrointestinal tract during GIIs, which is known to increase the leakiness of the gastrointestinal tract 
Table 2

Risk of dementia dependent on the cumulative number of preceding quarters with a GII diagnosis

\begin{tabular}{|c|c|c|c|c|c|c|c|c|c|c|c|c|}
\hline & \multicolumn{3}{|c|}{ Model 1} & \multicolumn{3}{|c|}{ Model 2} & \multicolumn{3}{|c|}{ Model 3} & \multicolumn{3}{|c|}{ Model 4} \\
\hline & OR & $p$ & $95 \% \mathrm{CI}$ & OR & $p$ & $95 \% \mathrm{CI}$ & OR & $p$ & $95 \% \mathrm{CI}$ & OR & $p$ & $95 \% \mathrm{CI}$ \\
\hline \multicolumn{13}{|c|}{$\begin{array}{l}\text { Number of quarters with a GII until diagnosis/index } \\
\text { date since } 2004\end{array}$} \\
\hline 0 & 1.00 & & & 1.00 & & & & & & & & \\
\hline 1 & 1.50 & $<0.001$ & $1.42-1.59$ & 1.49 & $<0.001$ & $1.40-1.58$ & & & & & & \\
\hline 2 & 1.73 & $<0.001$ & $1.54-1.94$ & 1.70 & $<0.001$ & $1.51-1.91$ & & & & & & \\
\hline$\geq 3$ & 1.68 & $<0.001$ & $1.43-1.97$ & 1.64 & $<0.001$ & $1.40-1.93$ & & & & & & \\
\hline \multicolumn{13}{|c|}{ Prescription of $\mathrm{AB}$ until diagnosis/index date since 2004} \\
\hline 0 & & & & 1.00 & & & & & & & & \\
\hline$\geq 1$ & & & & 1.10 & $<0.001$ & $1.06-1.15$ & & & & & & \\
\hline \multicolumn{13}{|l|}{ GIIs $\times$ AB } \\
\hline No GII \& no AB & & & & & & & 1.00 & & & & & 1.00 \\
\hline $1 \mathrm{GII} \&$ no $\mathrm{AB}$ & & & & & & & 1.92 & $<0.001$ & $1.69-2.19$ & 1.40 & $<0.001$ & $1.20-1.63$ \\
\hline 2 GIIs \& no $A B$ & & & & & & & 2.22 & $<0.001$ & $1.55-3.18$ & 1.65 & 0.017 & $1.09-2.49$ \\
\hline$\geq 3$ GIIs \& no $\mathrm{AB}$ & & & & & & & 2.22 & $<0.001$ & $1.26-3.92$ & 1.84 & 0.066 & $0.96-3.52$ \\
\hline $\bar{N}_{0}$ GII $\& \geq 1 \mathrm{AB}$ & & & & & & & 1.13 & $<0.001$ & $1.09-1.18$ & 0.90 & $<0.001$ & $0.86-0.95$ \\
\hline $1 \mathrm{GII} \& \geq 1 \mathrm{AB}$ & & & & & & & 1.59 & $<0.001$ & $1.48-1.70$ & 1.02 & 0.632 & $0.94-1.11$ \\
\hline 2 GIIs $\& \geq 1 \mathrm{AB}$ & & & & & & & 1.85 & $<0.001$ & $1.63-2.10$ & 0.99 & 0.926 & $0.86-1.15$ \\
\hline$\geq 3$ GIIs $\& \geq 1 \mathrm{AB}$ & & & & & & & 1.80 & $<0.001$ & $1.52-2.14$ & 0.94 & 0.554 & $0.77-1.15$ \\
\hline \multicolumn{13}{|c|}{ Chronic comorbidities at diagnosis/index date } \\
\hline Diabetes & & & & & & & & & & 1.28 & $<0.001$ & $1.22-1.34$ \\
\hline Cerebrovascular diseases & & & & & & & & & & 1.94 & $<0.001$ & $1.85-2.03$ \\
\hline Hypertension & & & & & & & & & & 1.14 & $<0.001$ & $1.07-1.22$ \\
\hline Ischemic heart disease & & & & & & & & & & 1.05 & 0.026 & $1.01-1.10$ \\
\hline Hypercholesterolemia & & & & & & & & & & 0.94 & 0.013 & $0.90-0.99$ \\
\hline Intracranial injuries & & & & & & & & & & 1.98 & $<0.001$ & $1.77-2.22$ \\
\hline Atrial fibrillation & & & & & & & & & & 1.38 & $<0.001$ & $1.31-1.45$ \\
\hline Noninfective enteritis and colitis & & & & & & & & & & 1.10 & 0.001 & $1.04-1.17$ \\
\hline \multicolumn{13}{|c|}{ Acute comorbidities at diagnosis/index date } \\
\hline Urinary tract diseases & & & & & & & & & & 2.60 & $<0.001$ & $2.44-2.77$ \\
\hline Pneumonia & & & & & & & & & & 4.27 & $<0.001$ & $3.68-4.95$ \\
\hline \multicolumn{13}{|c|}{ Institutionalization status at diagnosis/index date } \\
\hline Living at home & & & & & & & & & & 1.00 & & \\
\hline Living in nursing home & & & & & & & & & & 5.36 & $<0.001$ & $4.83-5.95$ \\
\hline Log likelihood & & -16038.648 & & & -16028.177 & & & -16017.273 & & & -13274.237 & \\
\hline$p$ value (log likelihood) & & $<0.001$ & & & $<0.001$ & & & $<0.001$ & & & $<0.001$ & \\
\hline Pseudo $\mathrm{R}^{2}$ & & 0.009 & & & 0.010 & & & 0.011 & & & 0.180 & \\
\hline
\end{tabular}

GII, gastrointestinal infection; $\mathrm{AB}$, antibacterials for systemic use; $\mathrm{OR}$, odds ratio; $\mathrm{CI}$, confidence interval 
Table 3

Risk of dementia by time since last GII

\begin{tabular}{|c|c|c|c|}
\hline & \multicolumn{3}{|c|}{ Model 5} \\
\hline & OR & $p$ & $95 \% \mathrm{CI}$ \\
\hline \multicolumn{4}{|l|}{ Time since last GII } \\
\hline Never GII & 1.00 & & \\
\hline Last GII at diagnosis/index date & 2.36 & $<0.001$ & $2.02-2.76$ \\
\hline Last GII 1-2 quarters prior to diagnosis/index date & 1.23 & 0.013 & $1.04-1.44$ \\
\hline Last GII $\geq 3$ quarters prior to diagnosis/index date & 1.01 & 0.824 & $0.94-1.08$ \\
\hline \multicolumn{4}{|l|}{ Chronic comorbidities at diagnosis/index date } \\
\hline Diabetes & 1.27 & $<0.001$ & $1.22-1.33$ \\
\hline Cerebrovascular diseases & 1.93 & $<0.001$ & $1.84-2.03$ \\
\hline Hypertension & 1.13 & $<0.001$ & $1.06-1.21$ \\
\hline Ischemic heart disease & 1.04 & 0.056 & $1.00-1.09$ \\
\hline Hypercholesterolemia & 0.94 & 0.005 & $0.90-0.98$ \\
\hline Intracranial injuries & 1.95 & $<0.001$ & $1.74-2.19$ \\
\hline Atrial fibrillation & 1.37 & $<0.001$ & $1.30-1.44$ \\
\hline Noninfective enteritis and colitis & 1.08 & 0.005 & $1.02-1.15$ \\
\hline \multicolumn{4}{|l|}{ Acute comorbidities at diagnosis/index date } \\
\hline Urinary tract diseases & 2.50 & $<0.001$ & $2.34-2.67$ \\
\hline Pneumonia & 4.10 & $<0.001$ & $3.53-4.75$ \\
\hline \multicolumn{4}{|l|}{ Institutionalization status at diagnosis/index date } \\
\hline Living at home & 1.00 & & \\
\hline Living in nursing home & 5.30 & $<0.001$ & $4.78-5.89$ \\
\hline Log likelihood & -13239.835 & & \\
\hline$p$ value (log likelihood) & $<0.001$ & & \\
\hline Pseudo $\mathrm{R}^{2}$ & 0.182 & & \\
\hline
\end{tabular}

GII, gastrointestinal infection; OR, odds ratio; CI, confidence interval.

for gut microbiota, microbial components and products, allowing them to be transported to the brain via blood where they can contribute to the impairment of the blood-brain barrier and neuroinflammation [29, 30]. Moreover, microbial products that have escaped the gastrointestinal tract can bind to and activate peripheral immune cells, inducing the release of proinflammatory cytokines as observed, for example, for lipopolysaccharides of Gram-negative bacteria after binding to Toll-like receptor 4 on macrophages and B cells [31]. This affects not only systemic but also CNS inflammation and injury, foremost through the activation of microglia and by increasing the permeability of the blood-brain barrier, which allows the entry of immune cells and inflammatory molecules into the brain [32].

Due to the structure of our data, we could not assess the role of recurring GIIs on the risk of dementia dependent on patients' $A P O E$ genotypes, which influences susceptibility to $\mathrm{AD}$ [23]. APOE4 is not only the greatest genetic risk factor for $\mathrm{AD}$ but also leads to blood-brain barrier dysfunction predicting cognitive decline, which would allow peripheral penetration of the brain by microbial components and pathogens, and proinflammatory cytokines [33]. Moreover, several studies suggest that $A P O E 4$ is tied to an increased susceptibility to several pathogens, including herpes simplex virus 1 (HSV-1), human immunodeficiency virus (HIV), or severe acute respiratory syndrome coronavirus 2 (SARS-CoV-2) [34-37]. Lastly, the $A P O E$ genotype influences the gut microbiome structure and function, by which it could also affect the risk of $\mathrm{AD}[38,39]$.

Interestingly, our data show that increasing numbers of preceding quarters with a GII diagnosis cumulatively augment the risk for dementia, supporting the association in a dose-response manner, even when adjusted for one or more prescriptions of antibiotics (Table 2, model 3). However, when adjusted for various comorbidities, especially urinary tract infections and pneumonia, increasing numbers of preceding quarters with a GII diagnosis still cumulatively augmented the risk for dementia among patients without a prescription for antibiotics but were harmless for those receiving antibiotics (Table 2, model 4), which warrants further studies.

Despite a careful study plan, this study has limitations. Because our data only contain individuals aged 50 years and older, we do not have information on the exposure to GIIs or antibiotics prior to the age of 50 and prior to 2004. Also, the data are based on health records, meaning they include only the medical histories of those individuals who sought medical attention. Especially, in the case of very short-term 
and acute infections of the gastrointestinal tract, people often abstain from seeking medical help which results in an underestimation of very mild cases. Furthermore, due to the data structure we cannot assess a potential interaction effect for the severity of GIIs. On that basis, severe GIIs may be more likely to predict dementia than mild GIIs. Detailed clinical data, such as results of stool or blood samples, biomarkers, or results of neuropsychological tests, are missing so that the validity of diagnoses could not be verified by clinical data. Moreover, there were factors known to be associated with dementia that are not available in health claims data, such as family history, educational attainment, the quantity and quality of social relationships, physical activity, and tobacco or alcohol consumption. Further, the AOK's proportions of people with lower income and low education is higher than in private or other public health insurers in Germany, which may lead to higher morbidity rates. We tried to capture this bias by including several comorbidities and nursing home status, which are in turn associated with a person's socio-economic status. Another limitation is that the actual onset of dementia is unknown. However, we take this issue into account by excluding individuals with dementia and possible prodromes of dementia, such as PD, stroke, and complications of stroke during the years 2004 and 2005, and we find that GIIs remain significantly associated with an elevated risk of dementia. We cannot completely exclude the possibility that our findings are coincidental and that both GIIs and dementia are correlated with a third, unquantified factor. Also, prodromal dementia patients may have a higher risk of developing GIIs. However, the correlation between GIIs and dementia risk disappears in patients with a prescription for $A B$, suggesting a causal relationship.

Our analyses rely on a large sample size with 23,354 dementia cases and 23,354 matched controls. Health claims data are only marginally biased due to attrition for reasons other than death as the data are complete over time and the rate of change between public health insurance funds is low, especially at the oldest ages. The medical diagnoses were not prone to recall bias. Selection bias by health care providers or self-selection into the study can be ruled out. Moreover, all insured individuals, regardless of their functional and cognitive status, were included in the study.

In conclusion, this is the first population-based nested case-control study that is given on a national basis showing an increased risk of dementia after
GIIs. The risk of dementia was increased with at least a single preceding GII diagnosis and further increased with the cumulative number of preceding quarters with a GII diagnosis among individuals without a prescription for antibiotics. The higher risk indicates a plausible biological association between GIIs and dementia. Our study has exploratory validity and is aimed to guide future research towards the investigation of underlying gastrointestinal pathogens and mechanisms by which GIIs could cause or contribute to dementia. Lastly, our findings should be considered by patients, clinicians, and health policy makers when assessing the relative risks and benefits of delivering clinical follow-up and monitoring patients with frequent gastrointestinal infections.

\section{ACKNOWLEDGMENTS}

We are grateful to WIdO - AOK Research Institute, for providing the data.

Authors' disclosures available online (https:// www.j-alz.com/manuscript-disclosures/21-0316r2).

\section{REFERENCES}

[1] Cryan JF, O'Riordan KJ, Sandhu K, Peterson V, Dinan TG (2020) The gut microbiome in neurological disorders. Lancet Neurol 19, 179-194.

[2] Gopalakrishnan V, Helmink BA, Spencer CN, Reuben A, Wargo JA (2018) The influence of the gut microbiome on cancer, immunity, and cancer immunotherapy. Cancer Cell 33, 570-580.

[3] Depommier C, Everard A, Druart C, Plovier H, Van Hul M, Vieira-Silva S, Falony G, Raes J, Maiter D, Delzenne NM, de Barsy M, Loumaye A, Hermans MP, Thissen JP, de Vos WM, Cani PD (2019) Supplementation with Akkermansia muciniphila in overweight and obese human volunteers: A proof-of-concept exploratory study. Nat Med 25, 10961103.

[4] Gilbert JA, Quinn RA, Debelius J, Xu ZZ, Morton J, Garg N, Jansson JK, Dorrestein PC, Knight R (2016) Microbiomewide association studies link dynamic microbial consortia to disease. Nature 535, 94-103.

[5] Morais LH, Schreiber HLt, Mazmanian SK (2021) The gut microbiota-brain axis in behaviour and brain disorders. Nat Rev Microbiol 19, 241-255.

[6] Nerius M, Doblhammer G, Tamgüney G (2019) GI infections are associated with an increased risk of Parkinson's disease. Gut 69, 1154-1156.

[7] Colombo AV, Sadler RK, Llovera G, Singh V, Roth S, Heindl S, Sebastian Monasor L, Verhoeven A, Peters F, Parhizkar S, Kamp F, Gomez de Aguero M, MacPherson AJ, Winkler E, Herms J, Benakis C, Dichgans M, Steiner H, Giera M, Haass C, Tahirovic S, Liesz A (2021) Microbiota-derived short chain fatty acids modulate microglia and promote Abeta plaque deposition. Elife 10, e59826. 
[8] Vogt NM, Kerby RL, Dill-McFarland KA, Harding SJ, Merluzzi AP, Johnson SC, Carlsson CM, Asthana S, Zetterberg H, Blennow K, Bendlin BB, Rey FE (2017) Gut microbiome alterations in Alzheimer's disease. Sci Rep 7, 13537.

[9] Harach T, Marungruang N, Duthilleul N, Cheatham V, Mc Coy KD, Frisoni G, Neher JJ, Fak F, Jucker M, Lasser T, Bolmont T (2017) Reduction of Abeta amyloid pathology in APPPS1 transgenic mice in the absence of gut microbiota. Sci Rep 7, 41802.

[10] Brandscheid C, Schuck F, Reinhardt S, Schafer KH, Pietrzik CU, Grimm M, Hartmann T, Schwiertz A, Endres K (2017) Altered gut microbiome composition and tryptic activity of the 5xFAD Alzheimer's mouse model. J Alzheimers Dis 56, 775-788.

[11] Dodiya HB, Kuntz T, Shaik SM, Baufeld C, Leibowitz J, Zhang X, Gottel N, Zhang X, Butovsky O, Gilbert JA, Sisodia SS (2019) Sex-specific effects of microbiome perturbations on cerebral Abeta amyloidosis and microglia phenotypes. J Exp Med 216, 1542-1560.

[12] Minter MR, Hinterleitner R, Meisel M, Zhang C, Leone V, Zhang X, Oyler-Castrillo P, Zhang X, Musch MW, Shen X, Jabri B, Chang EB, Tanzi RE, Sisodia SS (2017) Antibiotic-induced perturbations in microbial diversity during post-natal development alters amyloid pathology in an aged APPSWE/PS1DeltaE9 murine model of Alzheimer's disease. Sci Rep 7, 10411.

[13] Minter MR, Zhang C, Leone V, Ringus DL, Zhang X, Oyler-Castrillo P, Musch MW, Liao F, Ward JF, Holtzman DM, Chang EB, Tanzi RE, Sisodia SS (2016) Antibioticinduced perturbations in gut microbial diversity influences neuro-inflammation and amyloidosis in a murine model of Alzheimer's disease. Sci Rep 6, 30028.

[14] Newton JM, Surawicz CM (2011) Infectious gastroenteritis and colitis. In Diarrhea, Guandalini H, Vaziri H, eds. Humana Press, pp. 33-59.

[15] The top 10 causes of death, World Health Organization, http://www.who.int/mediacentre/factsheets/fs310/en/,

[16] Verdu EF, Riddle MS (2012) Chronic gastrointestinal consequences of acute infectious diarrhea: Evolving concepts in epidemiology and pathogenesis. Am J Gastroenterol 107, 981-989.

[17] Lindsay JA (1997) Chronic sequelae of foodborne disease. Emerg Infect Dis 3, 443-452.

[18] Lynch C (2020) World Alzheimer Report 2019: Attitudes to dementia, a global survey. Alzheimers Dement 16, e038255.

[19] (2020) 2020 Alzheimer's disease facts and figures. Alzheimers Dement 16, 391-460.

[20] Livingston G, Sommerlad A, Orgeta V, Costafreda SG, Huntley J, Ames D, Ballard C, Banerjee S, Burns A, CohenMansfield J, Cooper C, Fox N, Gitlin LN, Howard R, Kales HC, Larson EB, Ritchie K, Rockwood K, Sampson EL, Samus Q, Schneider LS, Selbaek G, Teri L, Mukadam N (2017) Dementia prevention, intervention, and care. Lancet 390, 2673-2734.

[21] O'Brien JT, Thomas A (2015) Vascular dementia. Lancet 386, 1698-1706.

[22] Daviglus ML, Bell CC, Berrettini W, Bowen PE, Connolly ES, Jr., Cox NJ, Dunbar-Jacob JM, Granieri EC, Hunt G, McGarry K, Patel D, Potosky AL, Sanders-Bush E, Silberberg D, Trevisan M (2010) National Institutes of Health State-of-the-Science Conference statement: Preventing Alzheimer disease and cognitive decline. Ann Intern Med 153, 176-181.

[23] Strittmatter WJ, Roses AD (1996) Apolipoprotein E and Alzheimer's disease. Annu Rev Neurosci 19, 53-77.
[24] Taylor DH, Jr., Ostbye T, Langa KM, Weir D, Plassman BL (2009) The accuracy of Medicare claims as an epidemiological tool: The case of dementia revisited. J Alzheimers Dis 17, 807-815.

[25] Doblhammer G, Fink A, Fritze T (2015) Short-term trends in dementia prevalence in Germany between the years 2007 and 2009. Alzheimers Dement 11, 291-299.

[26] Kim S, Covington A, Pamer EG (2017) The intestinal microbiota: Antibiotics, colonization resistance, and enteric pathogens. Immunol Rev 279, 90-105.

[27] Cattaneo A, Cattane N, Galluzzi S, Provasi S, Lopizzo N, Festari C, Ferrari C, Guerra UP, Paghera B, Muscio C, Bianchetti A, Volta GD, Turla M, Cotelli MS, Gennuso M, Prelle A, Zanetti O, Lussignoli G, Mirabile D, Bellandi D, Gentile S, Belotti G, Villani D, Harach T, Bolmont T, Padovani A, Boccardi M, Frisoni GB, INDIA-FBP Group (2017) Association of brain amyloidosis with proinflammatory gut bacterial taxa and peripheral inflammation markers in cognitively impaired elderly. Neurobiol Aging 49, 60-68

[28] Erny D, Hrabe de Angelis AL, Jaitin D, Wieghofer P, Staszewski O, David E, Keren-Shaul H, Mahlakoiv T, Jakobshagen K, Buch T, Schwierzeck V, Utermohlen O, Chun E, Garrett WS, McCoy KD, Diefenbach A, Staeheli P, Stecher B, Amit I, Prinz M (2015) Host microbiota constantly control maturation and function of microglia in the CNS. Nat Neurosci 18, 965-977.

[29] Leblhuber F, Geisler S, Steiner K, Fuchs D, Schutz B (2015) Elevated fecal calprotectin in patients with Alzheimer's dementia indicates leaky gut. J Neural Transm (Vienna) 122, 1319-1322.

[30] Camilleri M (2019) Leaky gut: Mechanisms, measurement and clinical implications in humans. Gut 68, 1516-1526.

[31] Takeuchi O, Akira S (2010) Pattern recognition receptors and inflammation. Cell 140, 805-820.

[32] Haruwaka K, Ikegami A, Tachibana Y, Ohno N, Konishi H, Hashimoto A, Matsumoto M, Kato D, Ono R, Kiyama H, Moorhouse AJ, Nabekura J, Wake H (2019) Dual microglia effects on blood brain barrier permeability induced by systemic inflammation. Nat Commun 10, 5816.

[33] Montagne A, Nation DA, Sagare AP, Barisano G, Sweeney MD, Chakhoyan A, Pachicano M, Joe E, Nelson AR, D'Orazio LM, Buennagel DP, Harrington MG, Benzinger TLS, Fagan AM, Ringman JM, Schneider LS, Morris JC, Reiman EM, Caselli RJ, Chui HC, Tcw J, Chen Y, Pa J, Conti PS, Law M, Toga AW, Zlokovic BV (2020) APOE4 leads to blood-brain barrier dysfunction predicting cognitive decline. Nature 581, 71-76.

[34] Steel AJ, Eslick GD (2015) Herpes viruses increase the risk of Alzheimer's disease: A meta-analysis. J Alzheimers Dis 47, 351-364.

[35] Wang C, Zhang M, Garcia G, Jr., Tian E, Cui Q, Chen X, Sun G, Wang J, Arumugaswami V, Shi Y (2021) ApoEisoform-dependent SARS-CoV-2 neurotropism and cellular response. Cell Stem Cell 28, 331-342 e335.

[36] Del Ser T, Fernandez-Blazquez MA, Valenti M, Zea-Sevilla MA, Frades B, Alfayate E, Saiz L, Calero O, Garcia-Lopez FJ, Rabano A, Medina M, Calero M (2021) Residence, clinical features, and genetic risk factors associated with symptoms of COVID-19 in a cohort of older people in Madrid. Gerontology 67, 281-289.

[37] Corder EH, Robertson K, Lannfelt L, Bogdanovic N, Eggertsen G, Wilkins J, Hall C (1998) HIV-infected subjects with the E4 allele for APOE have excess dementia and peripheral neuropathy. Nat Med 4, 1182-1184. 
[38] Tran TTT, Corsini S, Kellingray L, Hegarty C, Le Gall G, Narbad A, Muller M, Tejera N, O'Toole PW, Minihane AM, Vauzour D (2019) APOE genotype influences the gut microbiome structure and function in humans and mice: Relevance for Alzheimer's disease pathophysiology. FASEB $J$ 33, 8221-8231.
[39] Maldonado Weng J, Parikh I, Naqib A, York J, Green SJ, Estus S, LaDu MJ (2019) Synergistic effects of APOE and sex on the gut microbiome of young EFAD transgenic mice. Mol Neurodegener 14, 47. 